\title{
Anthelmintic Activity of Nigella sativa against Caenorhabditis elegans
}

\author{
Emine Sen ${ }^{1}$, Tugce Ogut ${ }^{2}$, Abdullah Olgun ${ }^{3}$, Ozgul Kisa $^{4, *}$ \\ ${ }^{1}$ Department of Biochemistry, Faculty of Pharmacy, Altinbas University, Istanbul, Turkey \\ ${ }^{2}$ Department of Pharmaceutical Microbiology, Faculty of Pharmacy, Altinbas University, Istanbul, Turkey \\ ${ }^{3}$ Department of Biochemistry, Faculty of Pharmacy, Istinye University, Istanbul, Turkey \\ ${ }^{4}$ Department of Medical Microbiology, Faculty of Medicine, Ufuk University, Ankara, Turkey
}

Received June 16, 2021; Revised July 29, 2021; Accepted August 22, 2021

\section{Cite This Paper in the following Citation Styles}

(a): [1] Emine Sen, Tugce Ogut, Abdullah Olgun, Ozgul Kisa, "Anthelmintic Activity of Nigella sativa against Caenorhabditis elegans," Advances in Pharmacology and Pharmacy, Vol. 9, No. 4, pp. 117 - 126, 2021. DOI: 10.13189/app.2021.090405.

(b): Emine Sen, Tugce Ogut, Abdullah Olgun, Ozgul Kisa (2021). Anthelmintic Activity of Nigella sativa against Caenorhabditis elegans. Advances in Pharmacology and Pharmacy, 9(4), 117 - 126. DOI: 10.13189/app.2021.090405.

Copyright $\odot 2021$ by authors, all rights reserved. Authors agree that this article remains permanently open access under the terms of the Creative Commons Attribution License 4.0 International License

\begin{abstract}
Increasing resistance against classical anthelmintic drugs makes discovering new anthelmintic compounds from natural plants important. Nigella sativa ( $N$. sativa) is used as a medicinal plant overall the world and is known to have anthelmintic activity. Caenorhabditis elegans (C. elegans), a common cost-effective model organism that is easily maintained, is useful to determine the anthelmintic activity of new compounds derived from natural products. In our study we aimed to evaluate through toxicity assays the nematocidal activity of $N$. sativa on $C$. elegans during its larval and adult stages. Different concentrations of $N$. sativa oil $(900,450$ and $270 \mathrm{mg} / \mathrm{mL}$ ) were tested and toxicity assessments were done under stereomicroscope by counting the number of surviving nematodes. This study showed that $N$. sativa essential oil significantly decreases survival of $C$. elegans in both larval and adult stages at $900 \mathrm{mg} / \mathrm{mL}$ final concentration. Larval-stage worms were more sensitive to $N$. sativa essential oil than were adults. We recommend further studies on other effects of $N$. sativa on C. elegans after removing the toxic compound(s) from the extract. The further discovery of $N$. sativa essential oil compounds responsible for anthelmintic activity and determination of their mechanisms of toxicity can pave the way toward new medicines.
\end{abstract}

Keywords Nigella sativa, Anthelmintic, Caenorhabditis elegans, Medicinal Plants, Phytotherapy, Herbal Medicine

\section{Introduction}

Soil-Transmitted Helminth (STH) infections are caused by intestinal nematodes. Unfortunately, one-fourth of the general population worldwide is infected with STH. These diseases are most common in places like tropical and subtropical regions where fresh water and sanitation are deficient. They cause malnutrition, anemia, retardation of development, and mental problems, especially among school-aged children [1, 2]. Nematodes also infect farm animals and crops, thereby adversely influencing food production yields and causing economic losses and they may also infect domestic pets. Since parasitic infections affect humans in mostly under-developed countries major discoveries of new anthelmintic human medicines arise generally from the veterinary field in developed countries [3].

World Health Organization's list of essential medicines used in the treatment and control of STH contains four anthelmintic medications: mebendazole, albendazole, pyrantel pamoate, and levamisole [4]. The first two are benzimidazoles and are mainly used in combinations with different medications against rare tropical diseases. Their usage in combination with other medications is important in preventing the development of resistance. One drawback of combination therapy can be an increase in 
adverse events, especially in children [2]. Resistance to current medications used to treat helminth infections in domesticated animals is a major issue for livestock as well as humans $[5,6]$. Thus the discovery of new and safe drugs against pathogenic worms is an important research area for the pharmaceutical industry. Medicinal plants can be a fruitful source of new anthelmintic drugs. Plants synthesize multiple secondary metabolites that have diverse chemical and biological functions including defense against pathogens $[7,8]$ and human understanding of the use of plants for therapeutic purposes has accumulated over generations. This knowledge has been assimilated by ethnopharmacy and traditional medicine systems [8-10].

Nigella sativa ( $N$. sativa) Linn. (family: Ranunculaceae), commonly known as black seed or black cumin, is one of the oldest medicinal plants, traditionally used in the Indian subcontinent, Arabian countries, and Europe as a natural remedy for symptoms including cough, headache, fever, dizziness, and eczema [11,12]. The seeds or their oil are used to increase milk production in lactating mothers, to relieve flatulence, and for diuresis and vermifuge. They are also consumed in the diet as components of food or spice [13-15]. N. sativa seeds contain saponin and fiber in addition to macronutrients and their fixed oil is rich with many essential and non-essential fatty acids and sterols. The essential oil contains secondary metabolites like nigellone, thymoquinone, thymol, carvacrol, and d-limonene [15].

Caenorhabditis elegans (C. elegans) is a microscopic, non-pathogenic. free-living soil nematode with hermaphrodite and male sexes. It is found in many parts of the world and survives by eating microorganisms mainly bacteria - as a food source. It is used as a common model organism in many fields including genomics, cell biology, neuroscience, and human development. It provides many advantages like a short life cycle and lifespan, stereotypical development, small size, simplicity of propagation and maintenance, and a well-studied genome. An adult hermaphrodite worm contains approximately 1000 somatic cells. It generates hundreds of offspring. The worm can be maintained in the laboratory where it is grown on agar plates or liquid media with Escherichia coli (E. coli OP50) as a food source. Studies with C. elegans were started as early as the 1960s. It has similar biological mechanisms with all animal species, especially entozoa. Therefore, it provides an advantageous model organism for discovering new anthelmintic compounds [16-23].

$N$. sativa was reported to have anthelmintic activity in chickens. When combined with ivermectin, the $N$. sativa's activity was found to be higher than that of either ivermectin or $N$. sativa used alone [24]. This suggests that the mechanism of $N$. sativa's anthelmintic activity is different from that of ivermectin. $N$. sativa has been shown to have strong anthelmintic activity against
Fasciola hepatica in buffalo [25, 26], against Hymenolepis nana [27, 28] and Aspiculuris tetrapetra [28] in mice, and against helminths generally in sheep [24, 29].

Thymoquinone, one of the secondary metabolites of $N$. sativa, has been reported to have anthelmintic activity through mechanisms like surface tegumental damage [30] and protein carbonylation-type oxidative damage [31] in Fasciola gigantica. Condensed tannins of $N$. sativa have been shown to disturb the intestinal mucosa of adult worms [32], destroying them. $N$. sativa has also been reported to inhibit egg-laying and create biocidal effects in Schistosoma mansoni [33].

In this study, we aimed to test whether $C$. elegans is a suitable and cost-effective model to study the mechanisms of nematocidal activity of $N$. sativa or other natural products to facilitate the discovery of new anthelmintic compounds.

\section{Methods}

\subsection{Materials}

Wild type C. elegans strain N2 (from CGC) was used in this study. It was provided by the CGC, which is funded by NIH Office of Research Infrastructure Programs (P40 OD010440). N. sativa oil was purchased from Zade Vital Company in Turkey. Each capsule $(900 \mathrm{mg} / \mathrm{ml})$ contained $88 \%$ unsaturated fatty acids extracted by cold press production. 5-Fluoro-2-deoxyuridine (FUDR) was purchased from Sigma Chemical Company (St. Louis, MO).

\subsection{Maintenance of C. elegans}

Worms were maintained on nematode growth media (NGM) containing plates with an Escherichia coli OP50 lawn at $22^{\circ} \mathrm{C}$. Standard worm plate culture conditions and worm picking techniques were used [21].

\subsection{Experimental Design}

NGM plates were prepared by standard procedures. When needed, 5-fluorouracil was added into NGM at a final concentration of 40 microM to inhibit DNA synthesis and generation of new progeny. E. coli OP50 was heat-killed by incubating at $65^{\circ} \mathrm{C}$ for 30 minutes and then used as a food source. $N$. sativa oil was dissolved in $50 \%$ ethanol to prepare the stock solution. In both larval and adult stage groups, $1 \%$ ethanol was used as a negative control and levamisole $(8 \mathrm{mg} / \mathrm{mL})$ as a positive control. In treatment groups $N$. sativa seed oil was tested at 900, 450, and $270 \mathrm{mg} / \mathrm{mL}$ final concentrations in adult stage groups and tested only at $900 \mathrm{mg} / \mathrm{mL}$ in larval stage groups (because it was the effective dose in adults). $N$. sativa oil was spread on NGM plates (Table 1). Each test plate 
contained 50 adults of $C$. elegans. For the larval stage experimental group, doses mentioned in Table 2 were applied on petri dishes and then hypochlorite synchronized eggs $(n=100)$ were transferred to each petri dish. Experiments were performed in duplicate.

\subsection{Anthelmintic, Toxicological and Life Span Assays}

All groups were observed under microscope (ZEISSS V8. Germany) at 24, 48, and 72 hours after the start of treatments for toxicological assessment. All worms were then followed daily and checked for viability until death with lifespan analysis. All phenotypes (dead worms, structural changes, etc.) were recorded. Only the plates used for adult worms contained 5-fluorouracil. Dead worms were removed from plates and recorded until all worms died. Worms having internal hatching and worms that were wounded and lost were censored. The experiments were duplicated. The experiments were performed at room temperature $\left(21-23^{\circ} \mathrm{C}\right)$.

\subsection{Statistical Analysis}

One-way ANOVA and Tukey's HSD test $(p<0.05)$ were used to analyze the data from toxicological assessment. The data from the lifespan assays were plotted using Kaplan-Meier analysis. Statistical significances of lifespans were analyzed by log-rank test. IBM SPSS Statistics 20 program and OASIS: Online Application for the Survival Analysis of Lifespan Assays
Performed in Aging Research were used for calculations [34].

\section{Results}

\subsection{Anthelmintic Properties of $N$. sativa}

When we analyzed the survival of worms exposed to 900,450 , and $270 \mathrm{mg} / \mathrm{mL}$ seed oil for 24,48 , and 72 hours, we found that the number of surviving adult worms was significantly decreased in the $900 \mathrm{mg} / \mathrm{mL}$ group. For this reason, we tested only this dose instead of all three doses for larval stage analyses.

\subsection{Toxicological Assessment}

In toxicity studies, adults with abnormal features were observed at all doses starting at 24 hours; there were no structural changes but some worms demonstrated a hook-like bending (data not shown). At 24 hours adults showed a significantly changed survival only in the group treated with $900 \mathrm{mg} / \mathrm{mL}$ of $N$. sativa oil compared with the control group; this change was not significant in other groups. When the groups were compared within themselves. There was no difference between the 450 and $270 \mathrm{mg} / \mathrm{mL}$ doses, while there were significantly less surviving worms in the $900 \mathrm{mg} / \mathrm{mL}$ dose group compared with other groups.

Table 1. Experimental groups and their characteristics for adult stage C. elegans studies.

\begin{tabular}{|l|l|l|}
\hline GROUPS & TREATMENT & FINAL CONCENTRATION \\
\hline Negative Control & $500 \mu \mathrm{L}$ from $50 \%$ Ethanol (stock solution) & $1 \%$ Ethanol \\
\hline Positive Control & $8 \mathrm{mg} / \mathrm{mL}$ Sitraks syrup (Levamisole) & $8 \mathrm{mg} / \mathrm{mL}$ Levamisole \\
\hline Concentration 1 & $0.5 \mathrm{ml} 900 \mathrm{mg} / \mathrm{mL}$ N. sativa seed oil & $900 \mathrm{mg} / \mathrm{mL}$. sativa seed oil \\
\hline Concentration 2 & $0.25 \mathrm{~mL} 100 \%$ Ethanol. $0.25 \mathrm{~mL} 900 \mathrm{mg} / \mathrm{mL} N$. sativa seed oil & $450 \mathrm{mg} / \mathrm{mL}$. sativa seed oil \\
\hline Concentration 3 & $0.35 \mathrm{~mL} 100 \%$ Ethanol. $0.15 \mathrm{~mL} 900 \mathrm{mg} / \mathrm{mL}$ N. sativa seed oil & $270 \mathrm{mg} / \mathrm{mL}$. sativa seed oil \\
\hline
\end{tabular}

Table 2. Experimental groups and their characteristics for larval stage C. elegans studies.

\begin{tabular}{|l|l|l|}
\hline Groups & Treatment & Final Concentration \\
\hline Negative Control & $500 \mu \mathrm{L}$ from $50 \%$ Ethanol (stock solution) & $1 \%$ Ethanol \\
\hline Positive Control & $8 \mathrm{mg} / \mathrm{mL}$ Sitraks syrup (Levamisole) & $8 \mathrm{mg} / \mathrm{mL}$ Levamisole \\
\hline Concentration & $0.5 \mathrm{ml} 900 \mathrm{mg} / \mathrm{mL}$ N. sativa seed oil & $900 \mathrm{mg} / \mathrm{mL}$ N. sativa seed oil \\
\hline
\end{tabular}




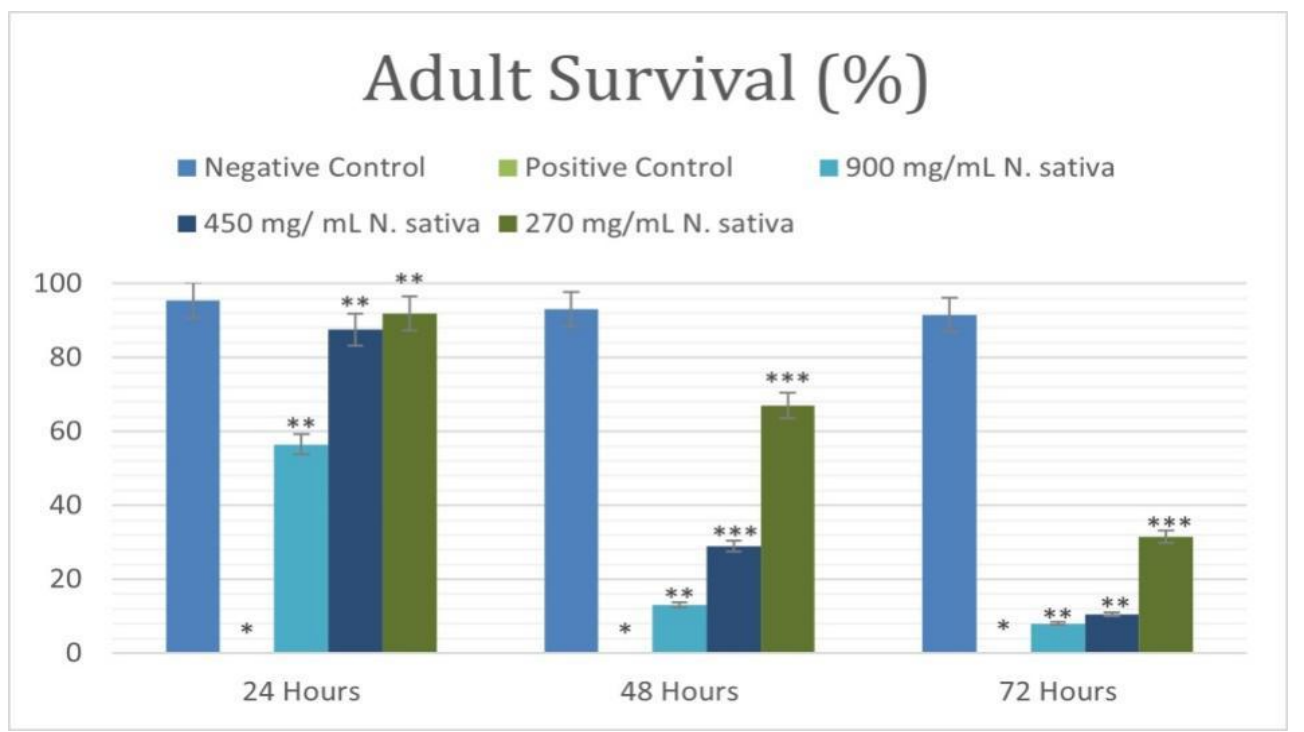

Figure 1. Adult survival percentages after short-term $N$. sativa oil exposure*; compared to negative control **; compared to negative and positive control; ***; and compared to negative and positive control and $900 \mathrm{mg} / \mathrm{ml} N$. sativa oil concentration $(\mathrm{p} \leq 0.05)$.

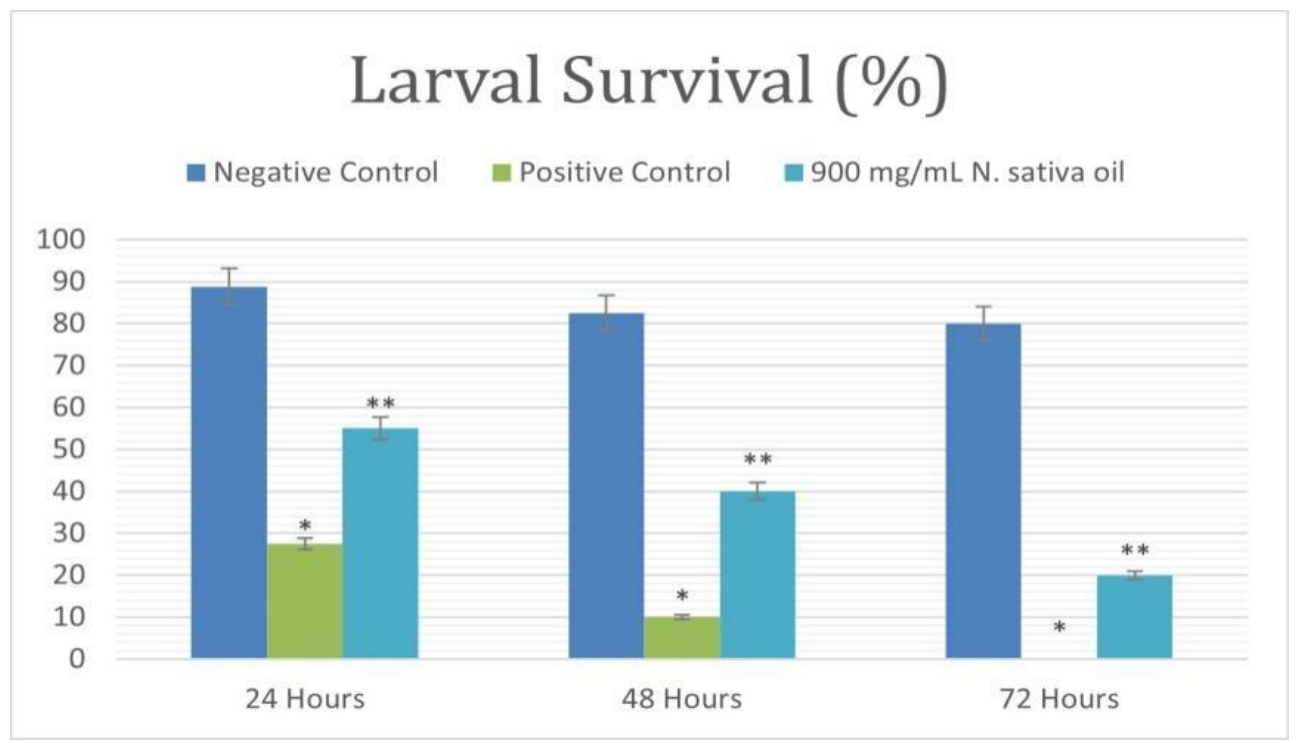

Figure 2. Larval survival percentage after short term N. sativa oil exposure*; compared to negative control**; and compared to negative and positive control $(\mathrm{p} \leq 0.05)$.

After 48 and 72 hours, the number of live adult worms was significantly decreased at all doses compared with the control group. At 72 hours, the $450 \mathrm{mg} / \mathrm{mL}$ dose was as effective as the $900 \mathrm{mg} / \mathrm{mL}$ dose (Figure 1). Similarly, the number and structural abnormalities of live larval worms was significantly decreased at all doses and treatment durations $(24,48$, and 72 hours after administration) (Figure 2).

\subsection{Life Span Analyses}

Maximum lifespans of experimental groups were recorded as 22 days in the negative control group, 8 days in the $900 \mathrm{mg} / \mathrm{Ml}$ group, 13 days in the $450 \mathrm{mg} / \mathrm{mL}$ group and 12 days in the $270 \mathrm{mg} / \mathrm{mL}$ group. Figure 3 and Table 3 show the results. According to statistical evaluations, lifespans were decreased significantly in all experimental groups compared with the control group. Table 3 does not show the positive control group's data because all animals in this group died within the first 24 hours. In larval groups, maximum lifespans were 16 days in the negative control group (ethanol), 3 days in the positive control group ( $8 \mathrm{mg} / \mathrm{mL}$ levamisole), and 5 days in the 900 $\mathrm{mg} / \mathrm{mL}$ group. Figure 4 and Table 4 show the results.

$N$. sativa seed oil at $900 \mathrm{mg} / \mathrm{mL}$ concentration was found to be more toxic than other doses (Figure 1.2.) and decreased the lifespan of $C$. elegans more than the other doses (Figure 3. 4.). When we compared the adult and larval worms at the concentration of $900 \mathrm{mg} / \mathrm{mL}$ of $N$. sativa seed oil, we found the maximum lifespans to be 8 days in adult and 5 days in larval groups. 
Table 3. Survival data of adult group's life span assay

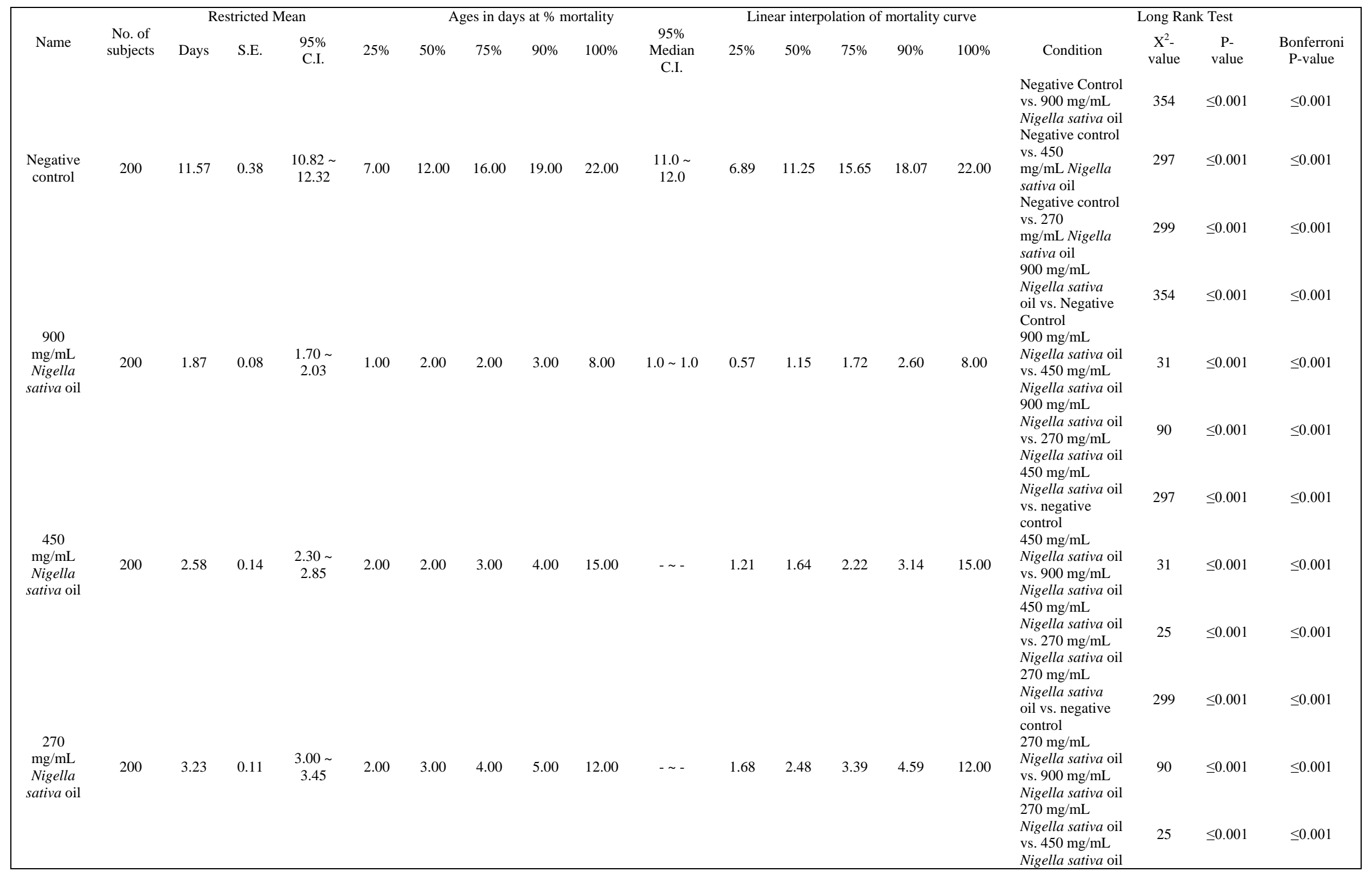


Table 4. Survival data of larval group's life span assay

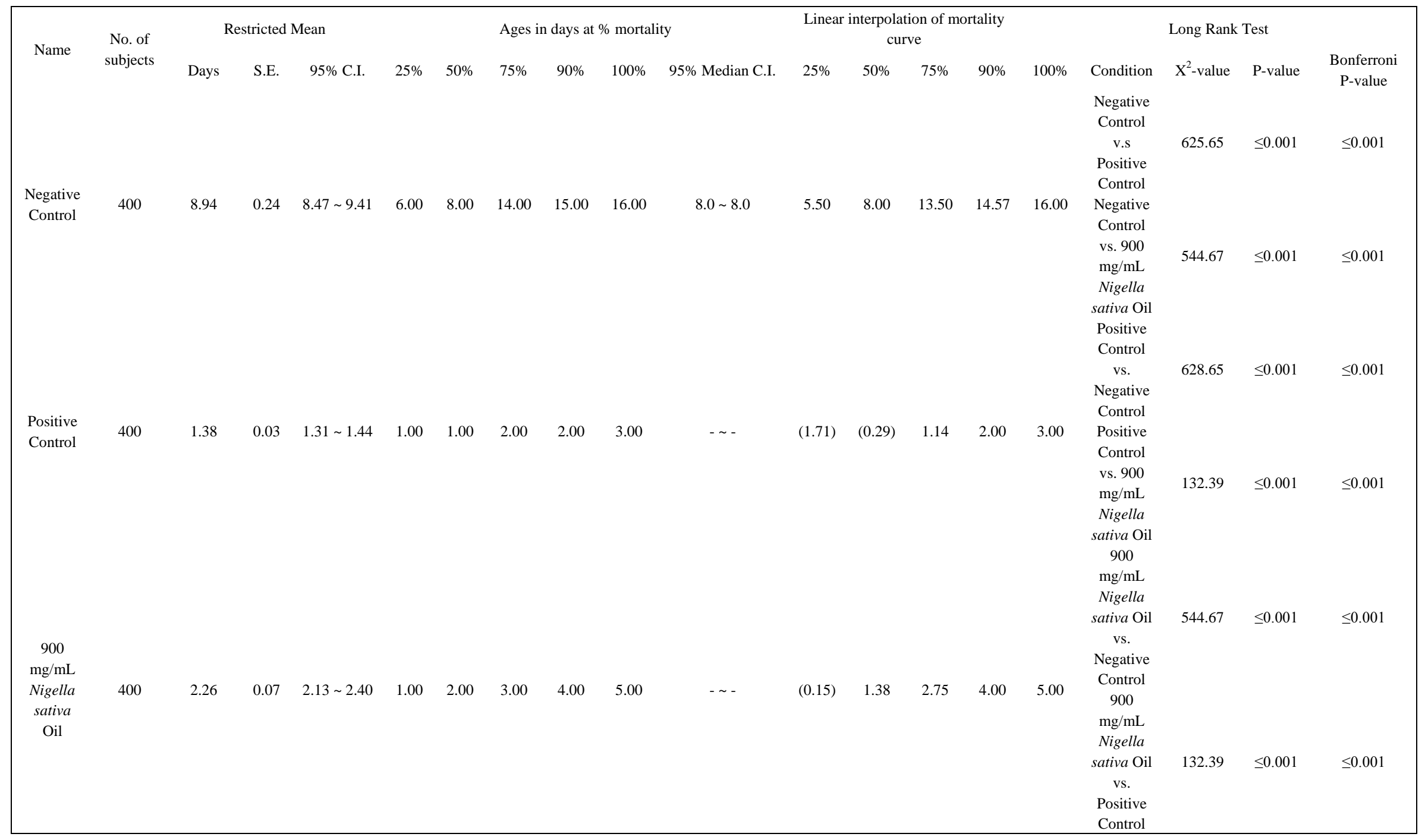




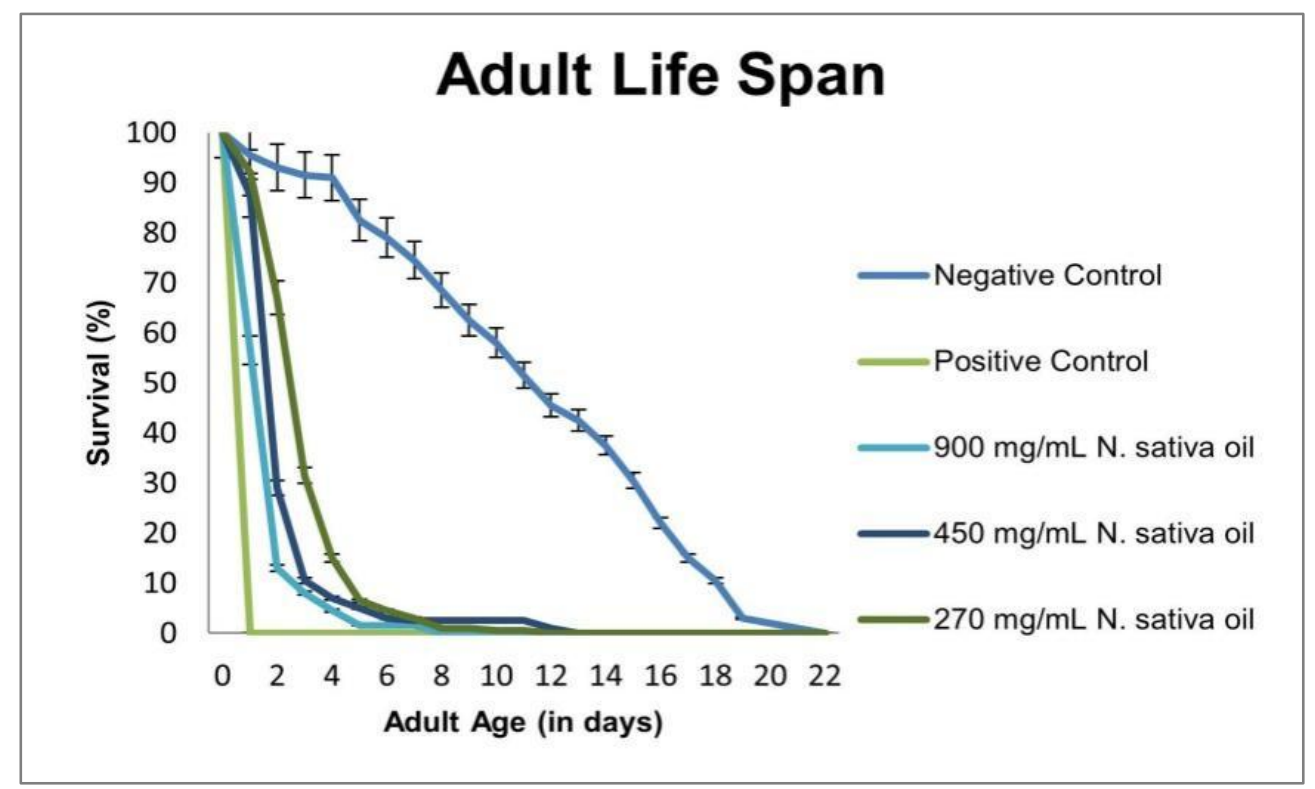

Figure 3. Adult stage life span assay

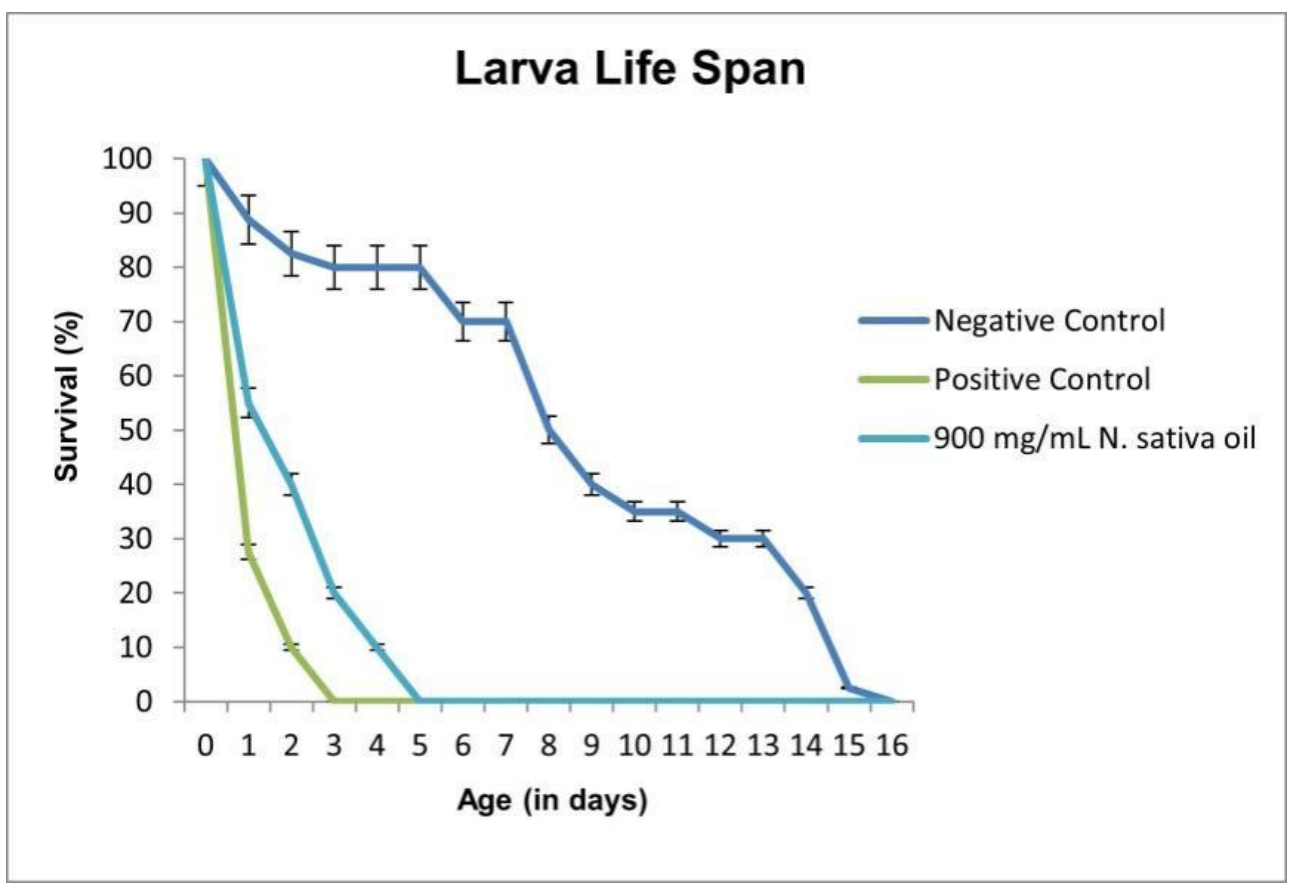

Figure 4. Larval stage life span assay

\section{Discussion}

A very cost-effective, easily maintained and readily accessible model organism, C. elegans has been used for research in various fields of biology and medicine. Since it is a nematode, its use in the discovery of new anthelmintics is not surprising [3, 16-20]. The seeds of $N$. sativa yield an essential oil possessing anthelmintic activity used against cestodes (flatworms) in children; and the same oil's ameliorating effect on liver damage caused by Schistosoma mansoni in mice has been previously reported [35], though the mechanisms of these effects and the responsible phytochemicals have not been identified. In this study, we aimed to prove the feasibility of $C$. elegans to investigate the mechanism of the anthelmintic activity of $N$. sativa oil. To this end, we tested the anthelmintic activity of $N$. sativa on C. elegans.

The crude alkaloid and water extracts of the $N$. sativa seeds have reportedly been effective against a variety of microorganisms, even drug-resistant ones [36], including Staphylococcus albus, Escherichia coli, Salmonella typhi, Shigella niger, and Vibrio cholera. Thymoquinone is one 
of the main compounds of $N$. sativa essential oil and inhibits non-enzymatic lipid peroxidation [40]. Gram-negative bacteria have a cell wall with a thicker lipid layer than gram-positive bacteria, making them more vulnerable to thymoquinone's lipid peroxidation activity. The epidermis of $C$. elegans contains an extracellular matrix (ECM) consisting primarily of collagen, lipids, and glycoproteins and thymoquinone has been reported to affect the organism's lipid structures [41, 42]. We observed that $N$. sativa oil destroyed the structural integrity of C. elegans (Figure 1.2).

Oral administration of the seed oil at doses of up to 10 $\mathrm{mL} / \mathrm{kg}$ in rats and mice did not cause any mortality or over-toxicity [43]. The LD50 value of thymoquinone is $2.4 \mathrm{~g} / \mathrm{kg}$ (range 1.52-3.77) [44]. Thymoquinone protects against hepatotoxicity [44] and $N$. sativa seeds are sold to treat conditions that include liver diseases [45]. Considering these facts, $N$. sativa seed oil can be considered for the prevention and treatment of many diseases.

Levamisole has a strong anthelmintic effect on $C$. elegans as reported in many previous studies [44]. The sensitivity of $C$. elegans to levamisole has been reported to be about 60 minutes [46] and our experiment observed a similar effect. Additionally, levamisole (positive control) had the same toxicity when larval and adult stage worms were compared. Abnormalities observed in larval stage were like Pdpy-7: tsp-15His and tsp-15 (sv15) mutant strains but in adult stage to tsp-15 (RNAi) phenotype (Figure 1.2).

We assessed both larval and adult animals to determine whether developmental periods affect the responses of $C$. elegans to $N$. sativa seed oil. $N$. sativa seed oil had the highest toxicity and lifespan shortening capability in $C$. elegans at $900 \mathrm{mg} / \mathrm{mL}$ concentration. At this concentration, the survival of adult and larval groups were 8 and 5 days, respectively. Larva were more sensitive, suggesting some protective mechanisms in adults.

This study demonstrated the anthelmintic and toxic activities of $N$. sativa oil against both larval and adult stages of $C$. elegans, finding the larval stage to be more sensitive. In further biological activity-guided purification studies investigating the secondary anthelmintic metabolite(s) of $N$. sativa oil, we can argue that $C$. elegans be used as a reliable, validated model.

\section{Acknowledgments}

Ozgul Kisa (Corresponding Author) was working at Department of Pharmaceutical Microbiology, Faculty of Pharmacy, Altınbaş University when this study was performed.

This study presented as poster presentation at 12th International Symposium on Pharmaceutical Sciences (ISOPS-12) which hold in Ankara, Turkey between June
$26-29,2018$

\section{Declaration of Interest}

The authors declare no conflicts of interest.

\section{Funding/Support}

This study received no specific financial support.

\section{REFERENCES}

[1] Keiser J., Utzinger J., "Efficacy of current drugs against soil-transmitted helminth infections: systematic review and meta-analysis." Journal of the American Medical Association, 299 (16): 1937-48, 2008. DOI: 10.1001/jama.299.16.1937.

[2] Reddy M., Gill SS., Kalkar SR., Wu W., “Anderson PJ et al. Oral drug therapy for multiple neglected tropical diseases: a systematic review." Journal of the American Medical Association, 298 (16):1911-1924, 2007. DOI: 10.1001/jama.298.16.1911

[3] Holden-Dye L. "Anthelmintic drugs.” WormBook, 44, 113, 2007. DOI: 10.1895/wormbook.1.143.1 <http:www.wormbok.org> Accessed date: 2018/12/26.

[4] Brooker S., Clements ACA., Bundy DAP. "Global Epidemiology. Ecology and Control of Soil-Transmitted Helminth Infections." Advances in Parasitology, 62 (5): 221-261, 2006. DOI: 10.1016/S0065-308X(05)62007-6.

[5] Geerts S., Gryseels B., "Drug resistance in human helminths: current situation and lessons from livestock." Reviews in Medical Microbiology, 13: 207-222, 2000. DOI: 10.1128/CMR.13.2.207.

[6] Waterman C., Smith RA., Pontiggia L., DerMarderosian A., "Anthelmintic screening of Sub-Saharan African plants used in traditional medicine." Journal of ethnopharmacology, 127 (3): 755-759, 2010. DOI: 10.1016/j.jep.2009.11.025.

[7] Ncube B., Van Staden J., "Tilting plant metabolism for improved metabolite biosynthesis and enhanced human benefit." Molecules, 20:12698-12731, 2015. DOI: 10.3390/molecules200712698.

[8] Ndhlala AR., Ghebrehiwot HM., Ncube B., Aremu AO., Gruz J., et al. "Antimicrobial. anthelmintic activities and characterisation of functional phenolic acids of Achyranthes aspera Linn.: A medicinal plant used for the treatment of wounds and ringworm in east Africa." Frontiers in Pharmacology, 6: 1-8, 2015. DOI: 10.3389/fphar.2015.00274.

[9] Cavalli-Sforza LL., Feldman MW., Chen KH., Dornbusch SM., "Theory and observation in cultural transmission." Science, 218: 19-27, 1982. DOI: 10.1126/science.7123211.

[10] Pennisi E., "Cultural evolution. Conquering by copying." 
Science, 328: $165-167, \quad 2010 . \quad$ DOI: 10.1126/science.328.5975.165.

[11] Nadkarni AK., "Indian Materia Medica" 1st ed., Bombay, India, 1976.

[12] Sayed MD., "Traditional medicine in health care." Journal of Ethnopharmacology, 2: 19-22, 1980. DOI: 10.1016/0378-8741(80)90023-9.

[13] Lautenbacher LM., Shwarzkümmelöl. Deutsche Apotheker Zeitung 137: 68-69, 1997.

[14] Ali BH., Blunden G., "Pharmacological and toxicological properties of Nigella sativa." Phytotherapy Research, 17: 299-305, 2003. DOI: 10.1002/ptr.1309.

[15] Bakal SN., Bereswill S., Heimesaat MM., "Finding novel antibiotic substances from medicinal plants-Antimicrobial properties of Nigella sativa directed against multidrug resistant bacteria." European Journal of Immunology, 7(1): 92-98, 2017. DOI: 10.1556/1886.2017.00001.

[16] Brenner S., "The genetics of behavior." British Medical Bulletin, 29: 269-271, 1973. DOI: 10.1093/oxfordjournals.bmb.a071019.

[17] Byerly L., Cassada RC., Russell RL., "The life cycle of the nematode Caenorhabditis elegans." Developmental Biology, 51: 23-33, 1976. DOI: 10.1016/0012-1606(76)90119-6.

[18] Sulston JE., Schierenberg E., White JG., Thomson JN., "The embryonic cell lineage of the nematode Caenorhabditis elegans." Developmental Biology, 100: 64-119, 1983. DOI: 10.1016/0012-1606(83)90201-4.

[19] Wood WB., "Introduction to C. elegans biology." In: W.B. Wood (ed). The nematode C. elegans Cold Spring Harbor Laboratory Press. Cold Spring Harbor. New York. 1-16, 1988.

[20] Lewis JA., Fleming JT., "Basic culture methods." In: Epstein HF. Shakes DC (editors). Caenorhabditis elegans. Modern biological analysis of an organism. Academic Press. California. 4-27, 1995.

[21] Stiernagle T., "Maintenance of C. elegans." In: Wormbook, 2006. DOI:10.1895/wormbook.1.101.1. <http:www.wormbok.org> Accessed date: 2018/12/26.

[22] Kennedy LM., Pham SC., Grishok A., "Nonautonomous regulation of neuronal migration by insulin signaling. DAF-16/FOXO. and PAK-1." Cell Report, 4 (5): 996-1009, 2013, DOI: 10.1016/j.celrep.2013.07.045.

[23] Katiki LM., Ferreira JFS., Zajac AM., Masler C., Lindsay DS., "Caenorhabditis elegans as a model to screen plant extracts and compounds as natural anthelmintics for veterinary use." Veterinary Parasitology, 182 (2-4): 264268, 2011, DOI: 10.1016/j.vetpar.2011.05.020.

[24] Angel C., Akhter N., Arijo A., Qureshi TA., Gandahi JA., Quazi IH., "Comparative efficacy of ivermectin and Nigella sativa against helminths in Aseel chickens (Gallus gallus domesticus)." Journal of Helminthology, 93(5):533-538, 2019, DOI: $10.1017 /$ S0022149X18000718.

[25] Kailani SR., Akhtar MS., Ashraf M., “Antifasciolic efficacy of indigenous plant drugs: kalonji. shahterah and karanjwa in buffaloes." Pakistan Journal of Pharmaceutical Sciences,
8(1):17-27, 1995, PMID: 16414763.

[26] Maqbool A., Hayat CS., Tanveer A., "Comparative efficacy of various indigenous and allopathic drugs against fasciolosis in buffaloes." Veterinarski Arhiv, 74: 107-114, 2004. https://hrcak.srce.hr/67837

[27] Al-Megrin WA., "Efficacy of black seeds oil (Nigella sativa) against Hymenolepis nana in infected mice." European Journal of Medicinal Plants, 13: 1-7, 2016. DOI: 10.9734/EJMP/2016/24773.

[28] Ayaz E., Yilmaz H., Ozbek H., Tas Z., Orunc O., “The effect of Nigella sativa oil against Aspiculuris tetraptera and Hymenolepis nana in naturally infected mice." Saudi Medical Journal, 28(11):1654-7, 2007. PMID: 17965783

[29] Al-Shaibani IRM., Phulan MS., Arijo A., Qureshi TA., Kumbhe AM., "Anthelmintic activity of Nigella sativa Linn. Seeds on gastrointestinal nematodes of sheep." Pakistan Journal of Nematology, 26: 207-218, 2008.

[30] Shalaby HA., Abu El Ezz NMT., Farag TK., Abou-Zeina HAA., In vitro efficacy of a combination of ivermectin and Nigella sativa oil against helminth parasites." Global Veterinaria, 9: 465-473, 2012.

[31] Ullah R., Rehman A., Zafeer M.. Rehman L., Khan YA et al. Anthelmintic Potential of Thymoquinone and Curcumin on Fasciola gigantica. PLoS One 12 (2):e0171267, 2017. DOI: 10.1371/journal.pone.0171267

[32] Athanasiadou S., Kyriazakis I., Jackson F., Coop RL., "Direct anthelmintic effects of condensed tannins towards different gastrointestinal nematodes of sheep: in vitro and in vivo studies." Veterinary Parasitology, 99(3):205-19, 2001. DOI: 10.1016/S0304-4017(01)00467-8

[33] Mohamed AM., Metwally NM., Mahmoud SS., "Nigella sativa seeds against Schistosoma mansoni various stages." Memorias do Instituto Oswaldo Cruz, 100 (2):205-11, 2005. DOI: $10.1590 /$ S0074-02762005000200016

[34] Yang JS., Nam HJ., Seo M., Han SK., Choi Y. et al., "OASIS: Online Application for the Survival Analysis of Lifespan Assays Performed in Aging Research." PLoS ONE 6 (8): e23525, 2011. DOI: 10.1371/journal.pone.0023525.

[35] Mahmoud MR., El-Abhar HS., Saleh S., "The effects of Nigella sativa oil against the liver damage induced by Schistosoma mansoni in mice." Journal of Ethnopharmacology, 79: 1-11, 2002. DOI: 10.1016/S0378-8741(01)00310-5

[36] Morsi NM., "Antimicrobial effect of crude extracts of Nigella sativa on multiple antibiotics-resistant bacteria." Acta Microbiologica Polonica 49: 63-74, 2000. PMID: 10997492

[37] Agarwal R., Kharya MD., Shrivastava R., “Antimicrobial and anthelmintic activities of the essential oil of Nigella sativa Linn." Indian Journal of Experimental Biology, 17: 1264-1265, 1979. DOI: /10.1016/S0378-8741(01)00310-5

[38] El-Kamali HH., Ahmed AH., Mohammed AS., Yahia IA., El-Tayeb IH., Ali A., "Antibacterial properties of essential oils from Nigella sativa seeds. Cymbopogon citatus leaves and Pulicaria undulata aerial parts." Fitoterapia, 34: 77-78, 1998. 
[39] Salem ML., Hossain MS., "Protective effect of black seed oil from Nigella sativa against murine cytomegalovirus infection." International journal of immunopharmacology, 22: 729-740, 2000. DOI: 10.1016/S0192-0561(00)00036-9

[40] Houghton PJ., Zarka R., de las Heras B., Hoult JRS., "Fixed oil of Nigella sativa and derived thymoquinone inhibit eicosanoid generation in leukocytes and membrane lipid peroxidation." Planta Medica, 61: 33-36, 1995. DOI: $10.1055 / \mathrm{s}-2006-957994$

[41] Chisholm AD., Hardin J., "Epidermal morphogenesis." 2005, DOI: 10.1895/wormbook.1.35.1. <http:www.wormbok.org> Accessed date: 2018/12/26.

[42] Page AP., Johnstone LL., "The cuticle." 2007, DOI:10.1895/wormbook.1.138.1.

<http:www.wormbok.org> Accessed date: 2018/12/26.
[43] Khanna T., Zaidi FA., Dandiya PC., "CNS and analgesic studies on Nigella sativa." Fitoterapia, 5: 407-410, 1993.

[44] Badary OA., Al-Shabanah OA., Nagi MN., Al-Bekairi AM., Almazar MMA., "Acute and subchronic toxicity of thymoquinone in mice." Drug Development Research, 44: 56-61, 1998.

DOI: 10.1002/(SICI)1098-2299(199806/07)44:2/3<56::AID-DD R2>3.0.CO;2-9

[45] Daba MH., Abdel Rahman MS., "Hepatoprotective activity of thymoquinone in isolated rat hepatocytes." Toxicology $\begin{array}{llll}\text { Letters, } & 95: & 23-29, & 1998 .\end{array}$ $10.1016 / \mathrm{s} 0378-4274(98) 00012-5$

[46] Schultz RD., Bennett EE., Ellis EA., Gumienny TL., "Regulation of extracellular matrix organization by BMP signaling in Caenorhabditis elegans." PLoS ONE, 9 (7): e101929, 2014. DOI: 10.1371/journal.pone.01019299. 